\title{
Comparison of three therapeutic interventions for chronic constipation in paediatric patients with cerebral palsy: a randomised clinical trial
}

\author{
Mohammad Hadi Imanieh¹, Mohammad Reza Golpayegan², Mostafa Sedighi ${ }^{3}$, Kamal Ahmadi $^{4}$, Abbas Aghaie $^{5}$, \\ Seyed Mohsen Dehghani ${ }^{1}$, Gholamreza Yousefi ${ }^{6}$ \\ ${ }^{1}$ Department of Paediatric Gastroenterology, Gastroenterohepatology Research Centre of Nemazee Hospital, Shiraz University \\ of Medical Sciences, Shiraz, Iran \\ 2Department of Paediatrics, Clinical Research Development Centre, Kermanshah University of Medical Sciences, Kermanshah, Iran \\ ${ }^{3}$ Department of Paediatric Neurology, School of Medicine, Kermanshah University of Medical Sciences, Kermanshah, Iran \\ ${ }^{4}$ School of Medicine, Kermanshah University of Medical Sciences, Kermanshah, Iran \\ ${ }^{5}$ Department of Epidemiology, School of Health, Kermanshah University of Medical Sciences, Kermanshah, Iran \\ ${ }^{6}$ Department of Paediatrics Gastroenterology, School of Medicine, Kermanshah University of Medical Sciences, Kermanshah, Iran
}

Key words: cerebral palsy, chronic constipation, polyethylene glycol, Motilium.

Address for correspondence: Gholamreza Yousefi Assist Prof., Department of Paediatrics Gastroenterology, School of Medicine, Kermanshah University of Medical Sciences, Kermanshah, Iran, e-mail: Dr.g.yousefi@gmail.com

\begin{abstract}
Introduction: Cerebral palsy (CP) is a permanent non-progressive movement disorder, which is due to brain injuries during brain development. Constipation is one of the prevalent conditions in children with CP that can adversely affect the psychological health, appetite, and overall health of these patients.

Aim: To compare three therapeutic methods in the treatment of chronic constipation in CP children.

Material and methods: In this randomised clinical trial (RCT), paediatric CP patients with chronic constipation were randomly divided into three groups (groups A, B, and C). Group A received polyethylene glycol (PEG), group B received PEG with Motilium, and group $C$ received Motilium for 2 weeks. Motilium was administered at $0.2 \mathrm{mg} / \mathrm{kg} / \mathrm{dose}$ and PEG at $0.5 \mathrm{~g} / \mathrm{kg} / \mathrm{dose}$ three times daily. To compare the therapeutic effect the McNemar test was used and a significance level of 0.05 was considered.

Results: The highest rate of improvement in chronic constipation was seen in group $B$ and the lowest rate belonged to group $C$. Satisfactory response frequency was seen in 10 patients in group A (58.8\%), 17 patients in group B (94.4\%), and 1 patient in group C (6.6\%); $p<0.001$.

Conclusions: According to the findings, simultaneous use of PEG and Motilium had the best therapeutic effect for chronic constipation among CP children. However, Motilium alone was nearly ineffective, and PEG alone had a moderate therapeutic effect.
\end{abstract}

\section{Introduction}

Cerebral palsy (CP) is a group of chronic movement and muscle tone disorders that result from injury to the central nervous system (CNS) during its development and can be associated with physical as well as psychological dysfunctions [1]. Cerebral palsy is a non-progressive neurologic condition that occurs during brain development. Because brain development mainly occurs in the first 2 years of life, CP can occur due to brain injury during the perinatal period or after birth [2]. Recent studies show that CP has a prevalence of 2.5 per 1000 births worldwide [3]. More than $70-80 \%$ of CPs occur congenitally with no identified cause. The risk factors for $\mathrm{CP}$ include preterm delivery (before 32 weeks of gestation), birth weight less than $2500 \mathrm{~g}$, intrauterine growth retardation (IUGR), intracranial bleeding, and trauma. Brain injury after birth can occur due to causes such as bacterial meningitis, viral encephalitis, hyperbilirubinaemia, accident trauma, or abuse of the neonate [4]. Besides movement deficits, which are exclusively called $\mathrm{CP}$, other abnormalities such as mental retardation, sei- 
zures, and speech problems can also be seen. Gastrointestinal problems like dysphagia, gastroesophageal reflux, difficulty in swallowing, gastric emptying delay, vomiting, and chronic constipation are also reported in CP children [5-7]. In children with chronic neurological dysfunction, gastrointestinal disorders are related to the severity of neurological dysfunction [8, 9]. Therefore, gastrointestinal and urinary disorders are more common in children with CP and spinal cord disorders.

Constipation is one of the common complaints in children with neurological disorders and is a manifestation of gastrointestinal disorders. Constipation can be the result of several items such as poor diet and decreased intestinal motility. Also, it is likely that with worsening of neurological dysfunction, presence of mental retardation, and decreased physical activity, constipation becomes more severe and more difficult to manage [10-13]. Evidence shows that the prevalence of constipation is higher in children with developmental and neurological disorders compared to healthy children $[3,8]$. In healthy children with regular gut function, defecation occurs three to four times weekly $[14,15]$. Constipation in children presents as hard stools, reduced number of defecations, stool retention, and painful defecation. Constipation affects appetite and quality of life of influenced children. Usual treatments offered to children with constipation include education, consumption of foods that are high in fibre, increasing drinking of fluids, exercise, and using stool softeners and laxatives [16]. Polyethylene glycol (PEG) is a non-poisonous polymer, soluble in water, with high molecular weight, and which does not absorb after ingestion. PEG acts as an osmotic agent and increases stool water content. Clinical studies have demonstrated that PEG is effective in the treatment of constipation in adults and children [17]. Domperidone (Motilium $\left.{ }^{\oplus}\right)$ is a peripheral dopamine antagonist which increases the smooth muscles motility of the stomach and small intestine. It has been also shown that Motilium affects oesophageal motility function [18].

\section{Aim}

Considering the high prevalence of constipation in children with CP, difficulties in the treatment of CP, difficulties in the management of constipation, and paucity of sufficient studies in this regard, we decided to compare PEG, Motilium, and simultaneous use of PEG and Motilium in the treatment of constipation in children with CP.

\section{Material and methods}

In this double-blinded randomised clinical trial (RCT), 52 children with $C P$ and chronic constipation referred to a paediatric specialty clinic were included. They were randomly divided into three groups: PEG (17 patients), PEG and Motilium (18 cases), and Motilium only (17 cases). Two patients in the Motilium group were excluded due to insufficient cooperation and lack of regular use of Motilium. CP had been diagnosed by a neurologist, and those who had chronic constipation were referred to a paediatric gastrointestinal clinic. The criteria for diagnosis of chronic constipation were hard/painful defecation, defecation frequency $\leq$ two times per week, large stool diameter, severe retention of stool, faecal incontinence ( $\geq$ once per week), and hard faecal mass on rectal examination. Children who met at least two of the above-mentioned criteria for at least 2 months were eligible for inclusion. In this study the exclusion criteria were: having an organic aetiology for constipation after taking history and performing physical examination, such as no hard stool retention in the rectal exam, hard anal sphincter, history of delayed meconium passage, expulsive bowel movement immediately after rectal exam, children who were not able to take the medications, and in the case that the parents did not give consent for participation in the study.

Randomisation and blinding was done. A sealed, numbered envelope was delivered to the patients. The numbers and treatment groups were recorded in another record. After the treatment period, which lasted for 2 weeks, the patients were visited again. The research team staff were blinded to the groups. The examining paediatrician was also blinded to the groups. A questionnaire was designed to document the characteristics and symptoms of the patients at baseline and 2 weeks after enrolment. Satisfactory outcome was defined as defecation > two times weekly, soft stool and no pain on defecation, no palpation of hard stool on abdominal examination, no faecal incontinence, not palpating hard and large stool on rectal examination, and no blood in stool.

The patients were divided into three groups. Group A received $P E G(0.5 \mathrm{~g} / \mathrm{kg} /$ dose $)$ three times daily, group $B$ received $P E G$ and Motilium three times daily, and group $C$ received Motilium $(0.2 \mathrm{mg} / \mathrm{kg} /$ dose $)$ three times daily. The bottles and taste of the medications were similar, and the maximum allowed doses for children were used. Of 50 patients, eight children had faecal incontinence, 28 had failure to thrive (FTT) or poor weight gain, and 14 had history of urinary tract infection (UTI).

\section{Statistical analysis}

The Kruskal-Wallis test was used to compare age and weight between the three groups and $\chi^{2}$ test for gender. The $\chi^{2}$ test was used to compare clinical findings at baseline. A comparison of changes of clinical 
Table I. Characteristics of the patients in the three treatment groups

\begin{tabular}{lccc} 
Group & \multicolumn{2}{c}{ Gender } & $\begin{array}{c}\text { Age, } \\
\text { mean } \pm \text { SD }\end{array}$ \\
\cline { 2 - 3 } & Female & Male & \\
\hline PEG & $9(52.94 \%)$ & $8(47.05 \%)$ & $5.85 \pm 2.1$ \\
\hline PEG and Motilium & $6(33.3 \%)$ & $12(66.6 \%)$ & $4.1 \pm 2.7$ \\
\hline Motilium & $6(40 \%)$ & $9(60 \%)$ & $5.8 \pm 3.5$
\end{tabular}

findings before and after enrolment was done with the McNemar test. The significance level was set at 0.05 .

\section{Results}

Of 50 included patients, there were 29 (58\%) male and 21 (42\%) female children with a mean \pm SD age of $5.2 \pm 2.91$ years (Table I). There was no significant difference regarding age, gender, weight, and clinical findings $(p>0.05)$. Mean \pm SDweight of the children in PEG, Motilium, and PEG + Motilium groups were, respectively, $13.63 \pm 6.82,13.93 \pm 4.53$, and $12.28 \pm 3.69 \mathrm{~kg}$ $(p=0.5)$ (Figure 1). The clinical findings of the children are presented in Table II.

After 2 weeks of treatment, significant differences were seen between the three groups regarding satisfactory response to the treatments $(p<0.001)$. Satisfactory response frequency was seen in 10 (58.8\%) patients in group A, 17 (94.4\%) patients in group B, and only $1(6.6 \%)$ patient in group C (Table III). The McNemar test results showed that PEG had a significant effect on improvement of symptoms such as frequency of defecations per week, defecation with large stool diameter, painful defecation, palpation of stool on abdominal examination, and presence of hard and large stool on rectal examination. However, PEG did not have significant effect on bloody stool and faecal incontinence. In the PEG + Motilium group, $94.4 \%$ of the patients had significant improvement in their symptoms, and just one patient did not have satisfactory response. The McNemar test showed that simultaneous use of PEG

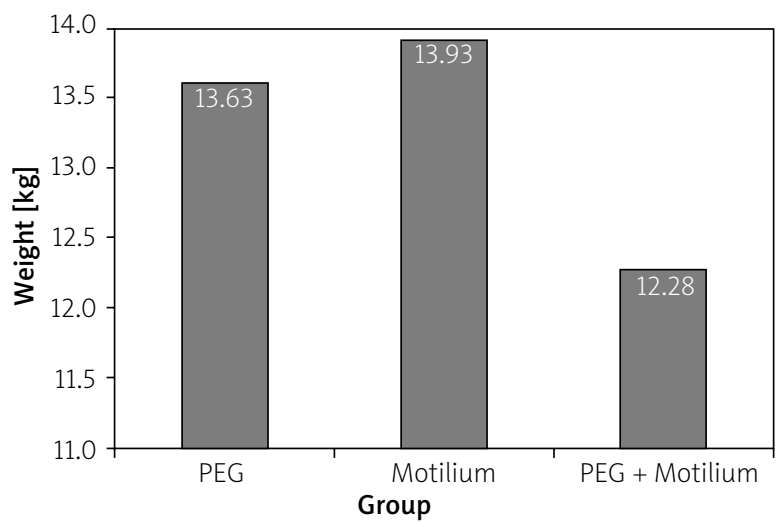

Figure 1. Mean weight of the children in the three treatment groups

and Motilium resulted in improvement of constipation. In the Motilium only group, only 1 patient had satisfactory response. The McNemar test showed that the symptoms of the patients did not improve after the treatment period when compared to baseline findings. A comparison of clinical findings at baseline and after 2 weeks of treatment is shown in Table IV.

\section{Discussion}

In this study, 50 children with CP and chronic constipation were included and were divided randomly into three treatment groups. After 2 weeks of treatment, more than $50 \%$ of the included children showed satisfactory response, and most of them were in the group that received PEG with Motilium. Children with $\mathrm{CP}$ experience gastrointestinal disorders due to alterations of CNS function and intestinal motility. In a study, it was observed that dietary problems and gastrointestinal disorders occur in more than $90 \%$ of children with brain disorders [19]. Difficulty in swallowing in such children can result in malnutrition and worsening of constipation. In the current study, 3 patients were feeding via gastrostomy tube (these 3 children were in the PEG group). Of these, only one child had satisfactory response and the other 2 children did not show

Table II. Frequency distribution of clinical findings at baseline in the three studied groups

\begin{tabular}{|c|c|c|c|c|}
\hline Variable & Group A (\%) & Group B (\%) & Group C (\%) & $P$-value \\
\hline Large stool diameter & 100 & 100 & 100 & 0.15 \\
\hline Defection fewer than two times weekly & 100 & 100 & 100 & 1 \\
\hline Faecal incontinence & 17.6 & 16.6 & 13.3 & 0.3 \\
\hline Bloody stool & 29.4 & 38.8 & 20 & 0.49 \\
\hline $\begin{array}{l}\text { Palpation of large and hard stool on abdominal } \\
\text { examination }\end{array}$ & 70.5 & 55.5 & 73.3 & 0.49 \\
\hline Large and hard stool on rectal examination & 100 & 94.2 & 100 & 0.18 \\
\hline
\end{tabular}


Table III. Frequency of satisfactory response to the treatments after 2 weeks

\begin{tabular}{lccc} 
Variable & Group A (\%) & Group B (\%) & 94.4 \\
\hline Defecation more than two times weekly & 52.9 & 100 & 13.3 \\
\hline Stool with normal diameter & 94.1 & 100 & 100 \\
\hline Defecation of soft and non-painful stool & 88.2 & 100 & 13.3 \\
\hline No palpation of hard stools on abdominal examination & 88.2 & 94.4 & 86.7 \\
\hline No faecal incontinence & 94.2 & 76.4 & 100 \\
\hline No hard/large stool on rectal examination & 88.2 & 86.6
\end{tabular}

$P<0.001$.

Table IV. Comparison of clinical findings at baseline and after 2 weeks of treatment between the three studied groups

\begin{tabular}{|c|c|c|c|c|c|c|c|c|c|}
\hline \multirow[t]{2}{*}{ Variable } & \multicolumn{3}{|c|}{ Group A } & \multicolumn{3}{|c|}{ Group B } & \multicolumn{3}{|c|}{ Group C } \\
\hline & $\begin{array}{l}\text { Baseline } \\
\text { (\%) }\end{array}$ & $\begin{array}{c}\text { Week } 2 \\
(\%)\end{array}$ & $P$-value & $\begin{array}{l}\text { Baseline } \\
\text { (\%) }\end{array}$ & $\begin{array}{c}\text { Week } 2 \\
(\%)\end{array}$ & $P$-value & $\begin{array}{l}\text { Baseline } \\
\text { (\%) }\end{array}$ & $\begin{array}{c}\text { Week } 2 \\
(\%)\end{array}$ & $P$-value \\
\hline $\begin{array}{l}\text { Defecation fewer than } \\
\text { two times weekly }\end{array}$ & 100 & 47.1 & 0.004 & 100 & 5.6 & $<0.001$ & 100 & 93.4 & 1 \\
\hline Large stool diameter & 100 & 5.9 & $<0.001$ & 100 & 0 & 0.001 & 100 & 86.7 & 1 \\
\hline $\begin{array}{l}\text { Defecation of hard stool } \\
\text { or painful defecation }\end{array}$ & 100 & 11.8 & $<0.001$ & 100 & 0 & $<0.001$ & 100 & 93.4 & 1 \\
\hline $\begin{array}{l}\text { Palpation of hard stool } \\
\text { on abdominal exam }\end{array}$ & 100 & 11.8 & 0.021 & 100 & 0 & 0.001 & 100 & 86.7 & 0.5 \\
\hline Faecal incontinence & 17.6 & 5.8 & 1 & 16.6 & 0 & 1 & 13.3 & 13.3 & 0.109 \\
\hline $\begin{array}{l}\text { Large and hard stool } \\
\text { on rectal exam }\end{array}$ & 100 & 23.6 & $<0.004$ & 100 & 5.6 & $<0.001$ & 88.8 & 93.4 & 1 \\
\hline Blood on stool & 29.4 & 11.8 & 0.375 & 20 & 0 & 0.016 & 38.8 & 13.4 & 1 \\
\hline
\end{tabular}

appropriate response to PEG treatment. Children with chronic constipation usually require long-term treatment with laxative agents. Therefore, the administered agents should be safe, effective, and without significant side effects [20]. PEG acts as an osmotic agent and by increasing water content softens the stool. In a study on 13.5 million laxatives used in the UK, it was reported that the most commonly administered agents were osmotic laxatives (47\%), followed by stimulants (38\%), and bulk-forming ones (15\%). Also, a systematic review of constipation treatment in children published in 2006 showed that osmotic laxatives were the most effective agents in this regard [21].

In the current study, all 17 patients in the PEG group had painful defecation of large and hard stools. Also, all of them had defecation frequency fewer than two times per week. After 2 weeks of treatment with PEG, 10 patients had appropriate response with defecation frequency of more than two times weekly. However, 15 pa- tients in this group had non-painful and soft defecation after the treatment, but with defecation frequency fewer than two times/week. In the PEG group, 5 patients had blood on stools, 4 patients improved, and only 1 patient reported bloody stools after the treatment period. In the PEG group, $17.6 \%$ of the patients had faecal incontinence. After the treatment period, about 5.8\% still had this complaint, and others did not report this. In agreement with the findings of this study, in a study that was performed in China in 2012, to compare lactulose and PEG in the treatment of chronic constipation, it was reported that PEG and lactulose were effective in $72.38 \%$ and $41.44 \%$ of the patients, respectively [22]. In another study by Dziechciarz et al. in 2015 in Poland, the effect of PEG on the treatment of a chronic constipation was studied. The patients were divided into two groups with high PEG dose $(0.7 \mathrm{~g} / \mathrm{kg} /$ day) and low-dose PEG $(0.3 \mathrm{~g} / \mathrm{kg} /$ day). It was shown that both groups responded to the administered doses and both regimens 
resulted in resolution of chronic constipation [23]. In another study to compare PEG with lactulose in the treatment of chronic constipation in children, $87 \%$ of the group that received PEG ( $3 \mathrm{~g} / \mathrm{kg} /$ day) responded to treatment after 4 weeks. However, to achieve such a response, 8 weeks of treatment with lactulose was required [24]. As observed in several studies, PEG is a safe agent and is effective without significant side effects in the treatment of chronic constipation in children.

Motilium has a significant prokinetic effect on the upper GI tract and is effective in the treatment of gastroesophageal reflux [25]. In a study it was reported that oral domperidone (Motilium) significantly resolved upper GI tract disorders such as nausea, vomiting, poor appetite, and burning sensation, However, it was ineffective in the treatment of constipation [26]. It was also observed in the present study that Motilium had minimal effect on constipation. In the Motilium group, all 15 patients had painful defecation with large and hard stools. After 2 weeks of treatment, only one patient had satisfactory response and had soft and non-painful defecation of stool with a frequency of more than two times weekly. In this group, $13.3 \%$ of patients had faecal incontinence, which, despite treatment with Motilium, did not resolve in any of the patients. Three patients had bloody stools, and improvement was documented in only 1 patient. Motilium does not pass through the blood-brain barrier and therefore does not affect the CNS. Hence, long-term use of this agent does not have significant side effects [27]. In the simultaneous PEG and Motilium group, the best outcome was observed, and only 1 patient did not show appropriate response. The effect of addition of Motilium to PEG is probably due to the effect of Motilium on the upper GI tract and improvement of gastric functions. On the other hand, PEG affects defecation due to its osmotic effect, which results in non-painful defecation.

\section{Conclusions}

Considering high prevalence of constipation in children with $C P$, treatment of this condition with effective and safe agents is important. We observed different therapeutic response in our three groups. The best response was observed in the group that received PEG and Motilium, followed by the group that only received PEG, and more than $50 \%$ of the patients experienced improvement of chronic constipation, and Motilium increased this effect

\section{Conflict of interest}

The authors declare no conflict of interest.

\section{References}

1. Giudice E, Staiano A, Capano G, et al. Gastrointestinal manifestations in children with cerebral palsy. Brain Dev 1999; 21 : 307-11.

2. Krigger KW. Cerebral palsy: an overview. Am Fam Physician 2006; 73: 91-100.

3. Campanozzi A, Capano G, Miele E, et al. Impact of malnutrition on gastrointestinal disorders and gross motor abilities in children with cerebral palsy. Brain Dev 2007; 29: 25-9.

4. Taylor F, National Institute of Neurological Disorders and Stroke (U.S.), Office of Science and Health Reports. Cerebral palsy: hope through research. Bethesda, Md.: The Institute, 2001. Accessed online September 28, 2005, at: http://www.ninds.nih. gov/disorders/cerebral_palsy/detail_cerebral_palsy.htm.

5. Staiano A, Cucchiara S, del Giudice E, et al. Disorders of oesophageal motility in children with psychomotor retardation and gastro-oesophageal reflux. Eur J Pediatr 1991; 150: 638-41.

6. Staiano A, del Guidice ED, Simeone D, et al. Cisapride in neurologically impaired children with chronic constipation. Dig Dis Sci 1996; 41: 870-4.

7. Sullivan PB. Gastrointestinal problems in the neurologically impaired child. Baillieres Clin Gastroenterol 1997; 11: 529-46.

8. Sony KF, Chong FRCP. Gastrointestinal problems in the handicapped child. Curr Opin Pediar 2001; 13: 441-6.

9. Sullivan PB. Gastrointestinal disorders in children with neurodevelopmental disabilities. Dev Disabil 2008; 14: 128-36.

10. Morad M, Nelson NP, Merrick J, et al. Prevalence and risk factors of constipation in adults with intellectual disability in residential care centers in Israel. Res Dev Disabil 2007; 28: 580-6.

11. Ozturk M, Oktem F, Kisioglu N, et al. Bladder and bowel control in children with cerebral palsy: case-control study. Croat Med J 2006; 47: 264-70.

12. Roijen LE, Postema K, Limbeek VJ, Kuppevelt VH. Development of bladder control in children and adolescents with cerebral palsy. Dev Med Child Neurol 2001; 43: 103-7.

13. Svedberg LE, Englund E, Malker H, Stener-Victorin E. Parental perception of cold extremities and other accompanying symptoms in children with cerebral palsy. Eur J Paediatr Neurol 2008; 12: 89-96.

14. Alcantara J, Mayer DM. The successful chiropractic care of pediatric patients with chronic constipation: a case series and selective review of the literature. Clin Chiopr 2008; 11: 138-47.

15. Gillespie MC, Price KJ. The management of chronic constipation. Paediatr Child Health 2008; 18: 435-40.

16. Wang MG, Wang BX. Initial therapy of constipation in children. J Appl Clin Pediatr 2006; 21: 446-8.

17. Corazziari E, Badiali D, Habib FI, et al. Small volume isosmotic polyethylene glycol electrolyte balanced solution (PMF-100) in treatment of chronic nonorganic constipation. Dig Dis Sci 1996; 41: 1636-42.

18. Barone JA. Domperidone: a peripherally acting dopamine2-receptor antagonist. Ann Pharmacother 1999; 33: 429-40.

19. Reilly S, Skuse D, Poblete X. Prevalence of feeding problems and oral motor dysfunction in children with cerebral palsy: a community survey. J Pediatr 1996; 129: 877-82.

20. Mach T. The brain-gut axis in irritable bowel syndrome clinical aspects. Med Sci Monit 2004; 10: 125-31. 
21. Pashankar DS. Childhood constipation: evaluation and management. Clin Colon Rectal Surg 2005; 18: 120-7.

22. Wang Y, Wang B, Jiang X, et al. Polyethylene glycol 4000 treatment for children with constipation: a randomized comparative multicenter study. Exp Ther Med 2012; 3: 853-6.

23. Dziechciarz P, Horvath A, Szajewska H. Polyethylene glycol 4000 for treatment of functional constipation in children. J Pediatr Gastroenterol Nutr 2015; 60: 65-8.

24. Aghapour A, Aarabi M, Semnani SH, et al. Polyethylene glycol versus lactulose in chronic pediatric constipation. Govaresh 2010; 15: 20-5.

25. Longo WE, Vernava AM $3^{\text {rd }}$. Prokinetic agents for lower gastrointestinal motility disorders. Dis Colon Rectum 1993; 36: 696-708.

26. Soykan I, Sarosiek I, Shifflett J, et al. Effect of chronic oral domperidone therapy on gastrointestinal symptoms and gastric emptying in patients with Parkinson's disease. Mov Disord 1997; 12: 952-7.

27. Reddymasu SC, Soykan I, McCallum RW. Domperidone: review of pharmacology and clinical applications in gastroenterology. Am J Gastroenterol 2007; 102: 2036-45.

Received: 12.03 .2019

Accepted: 28.03.2019 